Voix et Images

voixetimages

\title{
Sur la route, vues de l'intérieur
}

\section{Lucie Lequin}

Volume 20, numéro 3 (60), printemps 1995

André Brochu

URI : https://id.erudit.org/iderudit/201202ar

DOI : https://doi.org/10.7202/201202ar

Aller au sommaire du numéro

\section{Éditeur(s)}

Université du Québec à Montréal

\section{ISSN}

0318-9201 (imprimé)

1705-933X (numérique)

Découvrir la revue

\section{Citer cet article}

Lequin, L. (1995). Sur la route, vues de l'intérieur. Voix et Images, 20(3),

717-720. https://doi.org/10.7202/201202ar d'utilisation que vous pouvez consulter en ligne.

https://apropos.erudit.org/fr/usagers/politique-dutilisation/ 


\section{Sur la route, vues de l'intérieur}

\section{Lucie Lequin, Université Concordia}

Le dernier roman de Louis Hamelin, Betsi Larousse ${ }^{1}$, se termine côté sud du pont de Trois-Rivières; dans sa voiture, en route pour nulle part, Marc vit. Dans Le Visage d'Antoine Rivière ${ }^{2}$ de Micheline La France, la voiture d'Antoine s'écrase contre une église de l'île d'Orléans. Il meurt sur le coup. Quant à Impala $^{3}$ de Carole David, la Chevrolet Impala beige correspond au clinquant des années soixante - repris en écho visuel par la photo du film Song of Love en première de couverture - qui a piégé la mère de la narratrice et l'a finalement conduite au suicide. Dans ces trois romans, l'auto devient personnage et traduit, ici ou là, les rêves ratés ou ceux en devenir des protagonistes qui souffrent et se déplacent pour ne pas se figer dans l'envers de la vie. 
Betsi Larousse ou l'ineffable eccéité de la loutre parle de hasard, de route et de rencontres marquantes. En trois jours, la vie de Marc Carrière, un sculpteur en mal d'inspiration et de mouvement, se transforme. Sur la route de Mékinac, au volant de sa voiture, il se laisse prendre par les mots naïfs d'une ballade de Betsi Larousse, une jeune chanteuse populaire, qui le charme malgré lui. Distrait, il frappe un orignal qui traverse le pare-brise et atterrit à ses côtés, sur la banquette avant. Puis, sans trop le vouloir, il se rend à Saint-Tite où, par hasard, il rencontre un ami d'université, Yvan Lépine qui, comme lui, est fasciné par Betsi Larousse. De gestes en gestes, dans la démesure, ils rencontrent Betsi et son chien Caligula, avec qui ils passeront une longue fin de semaine au chalet de Marc. Le dimanche, chacun reprendra la route, sa propre route, et seul le hasard pourra provoquer une nouvelle rencontre. Trame romanesque somme toute banale - le ressourcement dans la nature et les grands espaces, par exemple - et cousue de hasard.

Par contre, ce roman analyse l'impact de la culture populaire: la musique rock, les ballades western, les 'chansons de Brel, les vedettes américaines, les clips québécois, et j'en passe, toutes ces marques culturelles qui, au jour le jour, fabriquent une manière d'être, de voir et de penser. La maladie des festivals, par exemple, est abordée avec brio et humour. L'intérêt du roman réside aussi dans ses réflexions philosophiques et ses belles descriptions de la Mauricie. Chaque personnage, à sa façon, recherche un certain absolu ou "l'ineffable eccéité de la loutre". Betsi représente "l'industrie de la courte vue" (p. 36) et tout son côté factice; à la fois complice et victime; elle ne sait plus qui elle est. Marc personnifie l'ambivalence du sculpteur qui souhaite capter le mouvement sans l'arrêter et corriger ainsi l'imperfection du monde. Lépine, aventurier solitaire et fou, court au-devant de nouveaux défis, son magnétophone toujours en marche, pour dicter ses mémoires sur le vif. Mais que dicte-t-il réellement? À quoi chacun joue-t-il? Enfin, le roman porte sur le désir inassouvi qui doit rester désintéressé et pur.

Un roman réussi, souvent ironique et où, en épilogue, la violence destructrice apporte une certaine sérénité. Alors pourquoi ce choix de noms de mauvais goût: l'un s'appelle Marc, son patronyme n'est presque jamais mentionné; l'autre se nomme Lépine, et son prénom est tu. À cet égard, il aurait mieux valu que l'auteur se censure plutôt que de jouer dans la transgression irrespectueuse. La réalité est encore trop proche. 


\section{***}

Le Visage d'Antoine Rivière parle aussi de culture, mais de la culture des gens de pouvoir de la bourgeoisie outremontoise. Dans ce milieu, les voitures sont luxueuses et dernier cri. Mais le factice y est aussi roi et maître. Ce roman saǹs prétention propose une enquête effectuée par Marc Léger, romancier et détective privé. Marc et Antoine Rivière se rencontrent à l'université. La curiosité de Marc, qui déjà veut devenir détective, est tout de suite aiguisée par l'attitude mystérieuse de ce nouvel ami. Qui est Antoine Rivière? Que cache son amnésie? Le passé, son passé, reconstitué pour lui par ses parents, ne provoque aucun déclic chez Antoine. Il naît à vingt ans et endosse l'identité qu'on lui offre.

Sous le couvert du polar, Micheline La France s'interroge sur l'apprentissage et l'usurpation de l'identité dans le Québec contemporain. Il y a là une exploration des mots "race " et "racines", et de l'envers de ce que les êtres sont. Fausse identité, amnésie, duperie, langue d'emprunt, visage refait et culture imposée constituent les ingrédients de l'enquête. L'auteure maintient le suspense avec efficacité. Cependant, l'allégorie, trop apparente, de la situation identitaire du Québec, dont l'importance de maîtriser son passé pour construire son avenir, agace plutôt qu'elle ne séduit. Dommage, car l'auteure a le sens du polar.

\section{$\stackrel{*}{* *}$}

"J'espère que personne n'a veillé sur ton âme " (p. 101), dit Louisa, la narratrice d'Impala, en pensant à son père. Devenue adulte, cette jeune femme tente de reconstituer la famille dont on l'a privée. Elle veut décanter les mensonges et les secrets, et comprendre la tourmente qui l'habite depuis sa tendre enfance, sa triste enfance. À partir de coupures de journaux, d'une lettre de sa mère qu'elle croyait morte et des souvenirs de sa tante Angelina qu'elle force à parler, mais si peu, Louisa redécouvre sa mère qu'elle n'a pas vue depuis des lannées et sonde l'abandon du père. L'écriture économe et dense de ce premier roman de Carole David laisse affleurer l'émotion intense, mais toujours discrète, d'une fille orpheline à cinq ans de parents vivants. À la fois chant d'amour à la mère et désillusion devant le poids de la tradition, le sobre récit de Louisa est porté par la voix de sa nécessité intérieure: "Laissez-moi me souvenir tandis qu'elle meurt pour la 
dixième fois. De Saint-Léonard à Rivière-des-Prairies en passant par la rue Dante, je n'ai jamais su qui j'étais. Suis-je la fille, véritablement la fille de Roberto?" (p. 16)

Cette quête de la vérité et des origines s'accomplit malgré la loi du silence. Comment Louisa peut-elle amener sa mère à parler de son emprisonnement et du rôle de Roberto dans sa vie? Qui Connie a-t-elle tué et pourquoi? Comment Louisa pourrait-elle pardonner à son père qui "[a] appris à vivre en état permanent de mensonge" (p. 115), lui qui a volé la voix et la vie de sa mère? Calmement, Louisa met fin à l'histoire et en raconte ensuite des bribes pour briser la loi du silence qu'elle a toujours refusée. Cette irruption de la parole advient dans la solitude; Louisa parle à un magnétophone. Toutefois, c'est une parole vivante laissant des traces indélébiles.

Carole David donne à lire un roman fort, marqué par l'économie de l'écriture poétique. Lorsqu'elle écrit "J'espère que personne n'a veillé sur ton âme" (p. 101), tout est dit au sujet du père, mais aussi sur les sentiments profonds de Louisa envers lui. Un roman rigoureux, tendu par l'émotion trop longtemps retenue, explorant le chemin que trace l'envers de la vie.

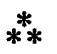

En quatrième de couverture du premier livre de Jeanne Le Roy, La Zébresse $e^{4}$, l'on dit que ce livre "marquera d'une pierre blanche la littérature érotique québécoise ". Une expectative est ainsi créée, surtout si l'on a suivi la fiction-théorie de l'érotisme au féminin des dernières décennies. Certes, l'auteure ne manque ni d'audace ni de vocabulaire. Mais l'inspiration relève de la pornographie banale et connue, sans plus, version cinéaste porno devenue écrivaine. On doit donc attendre avant de placer la pierre blanche.

1. Louis Hamelin, Betsi Larousse ou l'ineffable eccéité de la loutre, Montréal, XYZ éditeur, coll. "Romanichels ", 1994, 276 p.

2. Micheline La France, Le Visage d'Antoine Rivière, Montréal, l'Hexagone, 1994, $199 \mathrm{p}$.

3. Carole David, Impala, Montréal, Les Herbes rouges, 1994, 132 p.

4. Jeanne Le Roy, La Zébresse, Montréal, Les Herbes rouges, 1994, 136 p. 